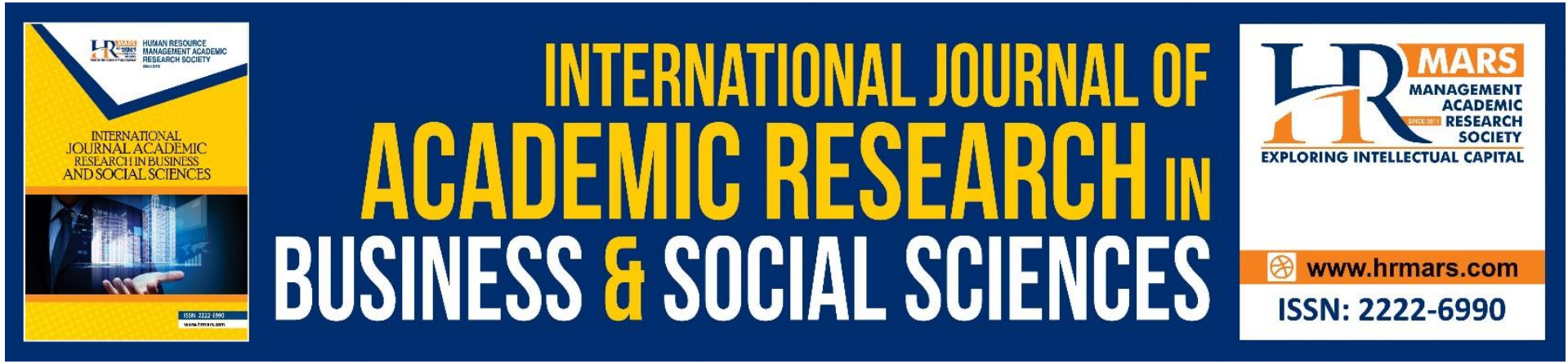

\title{
Relationship between Maternal Attachment and Behavioral Adjustment Problems among Children in Selangor, Malaysia
}

Wang Yin Tan, Nellie Ismail and Zarinah Arshat

To Link this Article: http://dx.doi.org/10.6007/IJARBSS/v11-i7/10098

DOI:10.6007/IJARBSS/v11-i7/10098

Received: 10 May 2021, Revised: 12 June 2021, Accepted: 28 June 2021

Published Online: 19 July 2021

In-Text Citation: (Tan et al., 2021)

To Cite this Article: Tan, W. Y., Ismail, N., \& Zarshat, A. (2021). Relationship between Maternal Attachment and Behavioral Adjustment Problems among Children in Selangor, Malaysia. International Journal of Academic Research in Business and Social Sciences, 11(7), 1023-1034.

Copyright: (c) 2021 The Author(s)

Published by Human Resource Management Academic Research Society (www.hrmars.com)

This article is published under the Creative Commons Attribution (CC BY 4.0) license. Anyone may reproduce, distribute, translate and create derivative works of this article (for both commercial and non-commercial purposes), subject to full attribution to the original publication and authors. The full terms of this license may be seen at: http://creativecommons.org/licences/by/4.0/legalcode

Vol. 11, No. 7, 2021, Pg. 1023 - 1034

http://hrmars.com/index.php/pages/detail/IJARBSS

JOURNAL HOMEPAGE

Full Terms \& Conditions of access and use can be found at http://hrmars.com/index.php/pages/detail/publication-ethics 


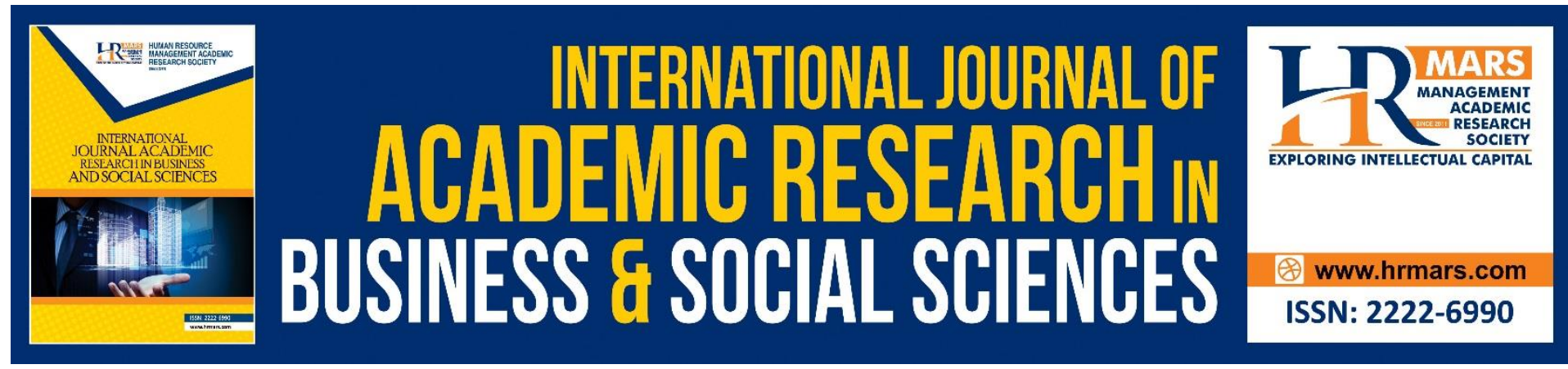

\title{
Relationship between Maternal Attachment and Behavioral Adjustment Problems among Children in Selangor, Malaysia
}

\author{
Wang Yin Tan, Nellie Ismail, and Zarinah Arshat \\ Department of Human Development \& Family Studies, Universiti Putra Malaysia, 43400 \\ Serdang, Malaysia. \\ Email:wytan2u@gmail.com, nellie@upm.edu.my,zarinah_upm@upm.edu.my
}

\begin{abstract}
Maternal attachment is known to be associated with children's behavioral adjustment problems. Behavioural adjustment problems that emerge during childhood often persist into adolescence and are associated with various negative outcomes. Therefore, this study aims to determine the relationship between maternal attachment and behavioral adjustment problems among children in Selangor, Malaysia. The specific objectives are to determine demographic factors, maternal attachment with behavioral adjustment. It is also to determine the differences in behavioral adjustment between male and female. By using multi-stage cluster random sampling technique, 400 married mothers of children (aged between 10 and 11) were selected from 22 primary schools in Selangor. Inventory of Parent and Peer Attachment (IPPA) and Strengths and Difficulties Questionnaire (SDQ) were used to measure maternal attachment and behavioral adjustment problems respectively. Results showed that children with higher educated mothers are less likely to develop behavioral adjustment problems. The results also revealed that boys have greater behavioral adjustment problems than girls. Yet, the results reported that higher scores of maternal attachment was associated with lower levels of children's behavioral adjustment problems. This study suggests that children who grow with a healthy attachment to their mothers stand a better chance of developing positive behaviors.
\end{abstract}

Keywords: Behavioral Adjustment Problems, Children, Externalizing, Internalizing, Maternal Attachment

\section{Introduction}

Over the last few years, the rate of behavioral adjustment problems has raised all over the countries including Malaysia. Children who born in Malaysia have the similar of specific trait of behaviour problems with children in other countries (Idris et al., 2019). Children in Malaysia reported highly rate in behaviour problems than British children (Farhana \& Suhaimi, 2012) and increasing the trend of mental health problems between aged 10 to 15 years old (NHMS, 2019). However, Idris et al (2019) had found that the rate of behavioral adjustment problems in Malaysia were also similar to Western countries. Behaviour problems occurred during children's early stage of development, which there is a significant modification of behaviour 
and personality. Behavioural adjustment problems have been categorized into two terms included internalizing problems and externalizing problems. Internalizing problems refers to too much of control by an individuals, includes of anxiety, depression, and social withdrawal (Mash \& Barkley, 2003). The term of externalizing problems defined as behaviour which under control by an individual (Mash \& Barkley, 2003) and also known as disruptive behaviour problems (Achenbach \& Ruffle, 2000), mainly refers to aggression, delinquency and hyperactivity (Achenbach \& Edelbrock, 1978). Most of the previous studies focused more in externalizing behaviour problems (Braza et al, 2015). There were only few existing literatures study on total behavioral problems (Hosokawa \& Katsura, 2018) and internalizing problems (Mesman et al., 2001). According to the World Health Organization (WHO) (2019), children who experienced behavioral adjustment problems may develop mental health problems in their future development.

Maternal factors such as maternal attachment play an important role in children's life outcomes, including behavioral adjustment problems. Maternal attachment refers to bonding and relationship between child and the primary caregiver (Bowlby, 1978). Previous studies found that sensitive and responsive mothers make children feel safe and less likely to have behavioral adjustment problems (Katsurada et al., 2017) compared to children who were insecurely attached to their mothers (Ensink et al., 2019). In addition to maternal attachment, demographic factors such as child's age and mother's years of education were also influence children's behavioral adjustment problems Children between aged 6 to 9 years old were found lower behavioral adjustment problems than older age children (Reiss, 2013). Also, there is a gender difference between male and female were found in the past research which male have higher level of externalizing problems than girls (Ahmad \& Mansor, 2016) but Guterman and Ari (2020) argued that boys have higher level of internalizing problems. The vast majority of existing researches on this topic have been widely conducted in Western countries. Therefore, this study aims to contribute to widening prior research particularly in Malaysian context.

\section{Objectives of the Study}

The main objective of this study is to determine the relationship between maternal attachment and behavioral adjustment problems among children in Selangor, Malaysia. The specific objectives are as followed:

1. To describe the respondent's background

2. To determine the relationship between demographic factors (child's age and mother's years of education) and maternal attachment with behavioral adjustment among children.

3. To determine the relationship between maternal attachment with behavioral adjustment among children.

4. To determine the differences in behavioral adjustment between male and female.

\section{Literature Review}

\section{Demographic and Behavioral Adjustment Problems}

Child development forms the basis of learning, behaviour and health in their life. Most of the previous found that children's age has a relationship with behavioral adjustment problems. Beaudoin et al (2013) indicated that older children had a higher level of externalizing behavioral problems and low level of internalizing behavioral problems compared to younger children (Cunningham et al., 2009). Also, the past study of Jin et al 
(2017) have found that middle age children (6 to 12 years) associated with children's externalizing problems. However, Reiss (2013) argued that 6 to 9 years old children were less likely to have behaviour problems Furthermore, child's sex also associated with behavioral adjustment during their development stages. According to Reiss (2013), boys tend to have greater behavioral adjustment problems than girls. Study by Braza et al. (2015) have found that externalizing problems and internalizing problems were both associated with males and females. Other study also demonstrated that males have more internalizing problems compared to females (Jin et al., 2017). This is supported by recent study conducted by Guterman and Ari (2020) which revealed that boys were more likely to faced internalizing problems as opposite to girls. In contrast, the study by Bongers et al. (2004) indicated that girls having more internalizing problems such as anxiety and depression compared to boys. Several studies have reported that boys are more likely to engage in externalizing behaviour problems than girls (Ahmad \& Mansor, 2016; Cheung et al., 2018).

Maternal education qualifications were strongly associated with behavioral adjustment problems among children. For instance, Hosokawa and Katsura (2018) indicated that lesseducated mothers are more likely to have children with behavioral adjustment problems. Similarly, Burlaka et al. (2015) found that maternal education level had greater impact on behavioral adjustment problems deeply impacted on behaviour problems of a child.

\section{Maternal Attachment and Behavioral Adjustment Problems}

Maternal attachment was one of the important stages during the development stage of a child. Mothers who provide care, low, supportive interaction with their children were more likely to exhibits secure attachment, yet children that lack of interactions and care from their mothers more likely to develop insure attachment (Smeekens et al., 2007). Previous studies have shown a relationship between secure attached and insecure attached with behavioral adjustment problems among middle-age children (Brumariu et al., 2012; Madigan et al., 2013). Another study also found a relationship between secure attachment and children's behavioral adjustment problems (i.e. depression, anxiety, aggressive) (Ensink et al., 2019), A recent study demonstrated that children with poor attachment have higher risk of behavioral adjustment problems (Dejko et al., 2020). Furthermore, children raised by sensitive and responsible mothers tend to have fewer behavioral adjustment problems (Nunes et al., 2013). Meanwhile, less responsive mothers were negatively correlated with behavioral adjustment among children (De Winter et al., 2018).

\section{Theoretical Perspective}

This study adopted Attachment Theory Ainsworth (1973); Bowlby (1969) as a theoretical framework. This theory was emphasized on the relationship and the interactions between the primary caregiver and the child. According to the theory, there were three types of attachment, that is, secure attachment, avoidant-insecure attachment, and resistanceinsecure attachment. Secure attachment is described by children who showed distress when their mother was not around and they might seek comfort from the strangers. Avoidant attachment is classified by children who tend to avoid or ignore mother's responses toward them and less likely to seek comfort from their mothers. Children with ambivalent attachment tend to display anger emotions on the mother's departure and feel uncomfortable when their mothers return (Ainsworth et al., 1978). Maternal attachment was strongly influenced on children's behavioral adjustment problems. Children with secure attachment were less likely to have difficulties in behavioral adjustment problems (Demby et al., 2017). Yet, poor 
attachment was found associated with children's behavioral adjustment problems such as internalizing and externalizing problems (Nunes et al., 2013).

Ecological System Theory (Bronfenbrenner, 1979) also supported above theory. This theory was emphasized more on interactions within family contexts and was strongly impacted on individual's development. In this theory was clearly explained and supported that reciprocal interactions between the relationships of mother-child was important and high impact on children's behavioral adjustment. This theory divided five different types of system, however only microsystem was related with present study. Microsystem is the basic layer describes as immediate surrounding for children. In current study, the term to highlight was the mother plays an important key role which directly impacted on children's development and outcomes.

\section{Materials and Methods}

Quantitative survey methodology was applied to gather information on the relationship between maternal attachment with behavioral adjustment problems among children. A set of $\mathrm{BI}$ and $\mathrm{BM}$ language online survey questionnaire (English-Malay) has been used for data collection. The questionnaire included the demographic background and standardized instruments. The questionnaire was designs and thus disseminated in the Google Forms application.

\section{Population and Sampling Procedures}

The present study was conducted in 22 government primary schools in Petaling and Hulu Langat Districts in Selangor. According to the Department of Statistics Malaysia (2018), Selangor had higher prevalence of behavioral adjustment problems among children (under age of 18 years old). The total population in this study consisted of 528,875 primary school children in Selangor states obtain from Ministry of Education Malaysia (2018). The population size was obtained from Ministry of Education Malaysia (2019). The sample size consisted of 400 married mothers of primary school children (aged between 10 and 11) in Petaling and Hulu Langat Districts in Selangor. The sample size was determined based on the sample size formulation by Cochran (1963). The sample in the current study was selected by using multistage cluster random sampling technique.

\section{Procedure}

This study was formally approved by the Ethics Committee for Research Involving Human Subjects, Universiti Putra Malaysia, Ministry of Education Malaysia and Selangor State Education Department. The purpose of ethics issues was to keep the confidential of the participants in the research that conducted. The researcher also needs to obtain permission from the principal to distribute the online questionnaire to the respondents. Data collection was carried out via online survey disseminated in the Google Form application and conducted in November 2020. A link containing the Google Forms survey was sent to all respondents through WhatsApp application, whereby they were provided with an informed consent prior to online survey completion.

\section{Variables and Measurements}

Maternal attachment was measured by using Inventory of Parent and Peer Attachment (Armsden \& Greenberg, 1987). The scale comprised 25 items and each of the item was scored based on 5-point Likert-type scale ranging from "Almost never or never true" (1) to "Almost 
always or always true" (5). Higher scores would indicate a higher level of maternal attachment. In the current study, the scale yielded a good reliability score as per its Cronbach's Alpha coefficient of .84 .

Children's behavioural adjustment problems have been measured by using Strengths and Difficulties Questionnaire (SDQ) (Goodman, 2001). The scale comprised 25 items rated on a 3-points Likert-typed scale ranging from $1=$ "Not true" to $3=$ "Certainly true". Higher score indicates higher levels of behavioral adjustment problems and the resulting Cronbach's Alpha value was .77 which excluded the prosocial subscales.

\section{Data Analysis}

The collected data were subjected to an analysis by using SPSS version 27. Descriptive statistics were used to describe the respondent's background (child's age and mother's years of education). Also, the inferential statistic such as Pearson's correlation was utilised to determine the relationship between respondent's background and maternal attachment with behavioural adjustment problems among children. Lastly, the independent sample t-test was used to determine the differences in behavioral adjustment problems between male and female.

\section{Results}

\section{Descriptive Analysis}

As shown in Table 1, more than half of the children (56.5\%) were 11 years old, while the remaining (43.5\%) (Mean=10.57) were 10 years old. Out of 400 children studied, 182 children were male and 218 were female. The results also showed that $53 \%$ of the mothers were between the age of 27 to 40 years old whereas $47 \%$ mothers were between the aged of 41 to 58 years old (Mean=40.45) In terms of maternal education, majority $(43.8 \%)$ mothers possessed a secondary qualification while $41.8 \%$ of the mothers possessed Bachelor's degree. 
Table 1. Distributions of respondent's background ( $N=400)$

\begin{tabular}{ll}
\hline Variables & N\% \\
\hline Child's Age (years) & $174(43.5 \%)$ \\
10 & $226(45.5 \%)$ \\
11 & \\
Mean = 10.57 & \\
Standard Deviation =.50 & \\
Child's Sex & $182(45.5 \%)$ \\
Male & $218(54.5 \%)$ \\
Female & \\
Mother's Age (years) & $213(53 \%)$ \\
$<40$ & $187(47 \%)$ \\
$>40$ & \\
Mean = 40.45 & \\
Standard Deviation $=5.61$ & \\
Mother's Education & \\
Never went to school & $2(0.5 \%)$ \\
Primary school & $27(6.8 \%)$ \\
Secondary school & $175(43.8 \%)$ \\
University & $167(41.8 \%)$ \\
Form 6 (STPM) & $4(1.0 \%)$ \\
Certificate & $5(1.3 \%)$ \\
Polytechnic & $6(1.5 \%)$ \\
Diploma & $9(2.3 \%)$ \\
College & $5(1.3 \%)$ \\
\hline
\end{tabular}

\section{Demographic Factors and Children's Behavioral Adjustment Problems}

Pearson's correlation analysis was used to analyse the relationship between demographic factors (child' age and mother's years of education) with children's behavioral adjustment problems (Table 2). The results showed that there is no significant relationship between child's age with behavioral adjustment problems among children ( $r=.03, p>0.05)$. Accordingly, mother's years of education $(r=-.11, p<0.01)$ was found to pose a significantly negative relationship with children's behavioural adjustment problems, demonstrating that higher levels of such elements may decrease children's behavioral adjustment problems.

Table 2. Pearson's correlation between demographic factors and children's behavioural adjustment problems

\begin{tabular}{lll}
\hline Variables & Behavioral Adjustment Problems \\
\hline & $\mathbf{r}$ & $\mathbf{p}$ \\
\hline Children's Age & .03 & .62 \\
Mother's Years of Education & $-.11^{*}$ & .02 \\
\hline
\end{tabular}

\section{Maternal Attachment and Children's Behavioral Adjustment Problems}

Table 3 showed that there was a negative significant relationship between maternal attachment and children's behavioral adjustment problems $(r=-.45, p<0.01)$. This result suggested that higher levels of maternal attachment were associated with lower levels of children's behavioral adjustment problems. 
Table 3. Pearson's correlation between maternal attachment and children's behavioural adjustment problems

\begin{tabular}{lll}
\hline Variable & \multicolumn{2}{l}{ Behavioral Adjustment Problems } \\
\hline & $\mathrm{r}$ & $\mathrm{p}$ \\
\hline Maternal Attachment (IPPA) & $-.45^{* *}$ & .00 \\
\hline
\end{tabular}

\section{Sex Differences in Behavioral Adjustment Problems}

Independent sample t-test analyses were conducted to determine the differences in children's behavioral adjustment problems between male and female. As shown in Table 4, there were significant differences in children's behavioral adjustment problems between male and female ( $t=3.52, p<0.05$ ). Male (Mean=29.46) have been found to have higher levels of behavioral adjustment problems compared to female (Mean=27.78). Based on the statistics table 4 showed that 182 males respondents with the total scores for behavioral adjustment $(M=29.46, S D=.38)$ was higher than the 218 females respondents $(M=27.78$, $S D=.29$ ). From the independent sample test indicated that there is a significant difference between both male and female $(p<0.05)$. In the column of equal variances assumed displayed the $t$-score of total scores for behavioral adjustment for both sex $(F=5.11),(t=3.57),(d f=398)$, $(p=<0.05)$.

Table 4. Independent sample t-test of children's behavioral adjustment problems

\begin{tabular}{lllll}
\hline Variables & Mean & SD & $\mathbf{t}$ & $\mathbf{p}$ \\
\hline Behavioral Adjustment Problems & & & 3.52 & 0.00 \\
Male & 29.46 & .38 & & \\
Female & 27.78 & .29 & & \\
\hline
\end{tabular}

\section{Disucssion}

This study aims to determine the relationship between demographic factors and maternal attachment with behavioral adjustment problems among children in Selangor. The results revealed that children with more educated mothers are less likely to have behavioral adjustment problems. The present findings support previous studies which were also found that low parental education was significant related with high level of internalizing problems (anxiety and depression) (Merz et al., 2018) and externalizing problems (Hosokawa \& Katsura, 2018). An educated mother have better mind set and emphasized on health inputs which might affected to their children outcome (Currie \& Goodman, 2020), and tend to understand children's need (Reiss, 2013).

Furthermore, the results demonstrated that boys were more likely to have behavioral adjustment problems compared to girls. Globally, in nationally representative surveys and cohort studies, boys have greater behavioral adjustment problems than girls (Blum et al., 2017). According to Reiss (2013) have found the similar results which males tend to have high level of behavioral adjustment problems than females. Also, boys might have more externalizing problems (Ahmad \& Mansor, 2016) and internalizing (Guterman \& Ari, 2020) compared to girls. However, Cheung et al (2018) argued that there is no gender difference in behavioral adjustment problems among children.

The results of the present study also suggest that higher levels of maternal attachment were associated with lower levels of children's behavioral adjustment problems. The results are consistent with findings of past studies which found that children with secure attachment have lower levels of behavioral adjustment problems such as depressive, anxiety and 
aggressive (Demby et al., 2017; Katsurada et al., 2017; Ensink et al., 2019; Spruit et al., 2020). While children with insecure attachment may leads to more behavioral adjustment problems (Madigan et al., 2013; Breinholst et al., 2019; Khan et al., 2020) such as internalizing problems (Katsurada et al., 2017) and externalizing problems (Nunes et al., 2013). The present results supported by the attachment theory Attachment Theory (Ainsworth 1973; Bowlby, 1969), and ecology system theory (Bronfenbrenner, 1979) which concluded that the bonding and interaction between mother and child was large influence on children's psychological outcomes.

Overall, these findings contribute to the growing body of literature by extending the understanding of this topic within the Malaysian context. The currents study offers practical implications as well. It can provide guidance for parents on how to shape and manage their children's behavioral adjustment problems. Besides, it may assist educators in planning interventions programs in the community for children who are struggling with behavioral adjustment problems. These findings may also useful for psychologist to plan a psychological intervention to observe children's behavioral adjustment problems and develop an efficient ways to solve and manage these problems.

There are several limitations of this study which should be highlighted and taken into consideration. First, the findings may not be able to generalizable to other primary schools in Malaysia as it involved only 22 primary schools in Selangor. Therefore, future studies are recommended to expand this study in various states in Malaysia with larger sample size to provide greater generalization and yield a more reliable data. Moreover, the present study did not attempt to investigate other potential factors that may influence behavioral adjustment problems among children such as parenting styles, peer relationship, home environment and socio-economic status. Further research might explore the influence of these factors on children's behavioral adjustment problems. Lastly, this study only used the Pearson's correlation and independent sample t-test analysis to analyze the data. Therefore, the direction of effects could not be determined. Future research should therefore use more advanced statistics to get more interesting findings about this topic.

Despite these limitations, the current findings add substantially to our understanding of how demographic factors and maternal attachment are related with children's behavioral adjustment problems. In conclusion, children with mother of high educated may not cause of behavioral adjustment problems. Also, from the results concluded that males have higher behavioral adjustment problems than females. Yet children with high secure attached may not lead to behavioral adjustment problems.

\section{References}

Achenbach, T. M., \& Edelbrock, C. S. (1978). The classification of child psychopathology: A review and analysis of empirical efforts. Psychological Bulletin, 85(6), 1275-1301. https://doi.org/10.1037/0033-2909.85.6.1275

Achenbach, T. M., \& Ruffle, T. M. (2000). The child behavior checklist and related forms for assessing behavioral/emotional problems and competencies. Pediatrics in Review, 21(8), 265-271. https://doi.org/10.1542/pir.21-8-265

Ahmad, N. F., \& Mansor, M. (2016). Externalizing behaviour problem among children age four and below in peninsular malaysia. Asian Journal of Social Sciences \& Humanities, 5(1), 16-17

Ainsworth, M. D. S., Blehar, M. C., Waters, E., \& Wall, S. (1978). Patterns of attachment: A psychological study of the strange situation. Hillsdale, N.J.: Erlbaum. 
Ainsworth, M. D. S. (1973). The development of infant-mother attachment, in Review of Child Development Research (Ed.) Cardwell B., Ricciuti H. /Chicago, IL: University of Chicago Press.

Armsden, G. C., \& Greenberg, M. T. (1987). The inventory of parent and peer attachment: individual differences and their relationship to psychological well-being in adolescence. Journal of Youth and Adolescence, 16(5), 427-454.

Beaudoin, G., Hébert, M., \& Bernier, A. (2013). Contribution of attachment security to the prediction of internalizing and externalizing behavior problems in preschoolers victims of sexual abuse. Revue Europeenne de Psychologie Appliquee, 63(3), 147-157. https://doi.org/10.1016/j.erap.2012.12.001

Blum, R. W., Mmari, K., \& Moreau, C. (2017). It begins at 10: How gender expectations shape early adolescence around the world. Journal of Adolescent Health, 61(4), S3-S4. https://doi.org/10.1016/j.jadohealth.2017.07.009

Bongers, I. L., Koot, H. M., Van Der Ende, J., \& Verhulst, F. C. (2004). Developmental trajectories of externalizing behaviors in childhood and adolescence. Child Development, 75(5), 1523-1537. https://doi.org/10.1111/j.1467-8624.2004.00755.x

Bowlby, J. (1969). Attachment. Attachment and loss: Vol. 1. Loss. New York: Basic Books.

Bowlby, J. (1978). Attachment theory and its therapeutic implications. Adolescent Psychiatry 6:5-33.

Braza, P., Carreras, R., Muñoz, J. M., Braza, F., Azurmendi, A., Pascual-Sagastizábal, E., Sánchez-Martín, J. R. (2015). Negative maternal and paternal parenting styles as predictors of children's behavioral problems: moderating effects of the child's sex. Journal of Child and Family Studies, 24(4), 847-856.

Breinholst, S., Tolstrup, M., \& Esbjørn, B. H. (2019). The direct and indirect effect of attachment insecurity and negative parental behavior on anxiety in clinically anxious children: it's down to dad. Child and Adolescent Mental Health, 24(1), 44-50. https://doi.org/10.1111/camh.12269

Bronfenbrenner, U. (1979). The ecology of human development: Experiments by nature and design. Cambridge, England: Havard University Press.

Brumariu, L. E., Kerns, K. A., \& Seibert, A. (2012). Mother-child attachment, emotion regulation, and anxiety symptoms in middle childhood. Personal Relationships, 19(3), 569-585. https://doi.org/10.1111/j.1475-6811.2011.01379.x

Burlaka, V., Bermann, E. A., \& Graham-Bermann, S. A. (2015). Internalizing problems in at-risk preschoolers: associations with child and mother risk factors. Journal of Child and Family Studies, 24(9), 2653-2660. https://doi.org/10.1007/s10826-014-0067-5

Cheung, R. Y. M., Boise, C., Cummings, E. M., \& Davies, P. T. (2018). Mothers' and fathers' roles in child adjustment: parenting practices and mothers' emotion socialization as predictors. Journal of Child and Family Studies, 27(12), 4033-4043. https://doi.org/10.1007/s10826-018-1214-1

Department of Statistic Malaysia. (2018). Children Statistics Publication, Malaysia. Retrieved June 8, 2020, from

https://www.dosm.gov.my/v1/index.php?r=column/pdfPrev\&id=RWsxR3RwRVhDRIJkK 1BLalgrMGRIQT09\#: :text=\%2C\%20the\%20composition\%20of\%20children\%20under,th an\%20female\%20(4.55\%20million).\&text=The\%20number\%20of\%20male\%20and,and \%201.26\%20million\%20persons\%20respectively.

Cochran, W. G. (1963). Sampling Techniques. (2nd Ed.). New York: John Wiley and Sons, Inc. Cunningham, J. N., Kliewer, W., \& Garner, P. W. (2009). Emotion socialization, child emotion 
understanding and regulation, and adjustment in urban African American families: Differential associations across child gender. Development and Psychopathology, 21(1), 261-283. https://doi.org/10.1017/S0954579409000157

Currie, J., \& Goodman, J. (2020). Parental socioeconomic status, child health, and human capital. In The Economics of Education: A Comprehensive Overview, 2, 239-248. https://doi.org/10.1016/B978-0-12-815391-8.00018-5

Dejko-Wańczyk, K., Janusz, B., \& Józefik, B. (2020). Understanding the externalizing behavior of school-age boys: the role of a mother's mentalization and attachment. Journal of Child and Family Studies, 29(1), 155-166. https://doi.org/10.1007/s10826-019-01543-0

Demby, K. P., Riggs, S. A., \& Kaminski, P. L. (2017). Attachment and family processes in children's psychological adjustment in middle childhood. Family Process, 56(1), 234-249. https://doi.org/10.1111/famp.12145

De Winter, S., Waters, T. E. A., Braet, C., \& Bosmans, G. (2018). Middle childhood problem behaviors: testing the transaction between responsive parenting, temperament, and attachment-related processing biases. Journal of Child and Family Studies, 27(3), 916927. https://doi.org/10.1007/s10826-017-0924-0

Ensink, K., Borelli, J. L., Normandin, L., Target, M., \& Fonagy, P. (2019). Childhood sexual abuse and attachment insecurity: associations with child psychological difficulties. American Journal of Orthopsychiatry, 90(1), 115.

Farhana, A., \& Suhaimi, H. (2012). Estimates of childhood behavioural problems in Malaysia and their relationship with parenting behaviour. Retrieved July 16, 2020, from https://eprints.utas.edu.au/20781/

Goodman, R. (2001). Psychometric properties of the strengths and difficulties questionnaire. Journal of the American Academy of Child and Adolescent Psychiatry, 40(11), 1337-1345.

Guterman, O., Ari, N. (2020). Parental attachment and internalizing and externalizing problems of Israeli school-goers and homeschoolers Parental attachment and internalizing and externalizing problems of Israeli school-goers and homeschoolers. School Psychology, 35(1), 41-50.

Hosokawa, R., \& Katsura, T. (2018). Effect of socioeconomic status on behavioral problems from preschool to early elementary school - A Japanese longitudinal study. PLOS ONE, 13(5). https://doi.org/10.1371/journal.pone.0197961

Idris, I. B., Barlow, J., \& Dolan, A. (2019). A longitudinal study of emotional and behavioral problems among malaysian school children. Annals of Global Health, 85(1).

Jin, Z., Zhang, X., \& Han, Z. R. (2017). Parental emotion socialization and child psychological adjustment among chinese urban families: mediation through Child Emotion Regulation and Moderation through Dyadic Collaboration. Frontiers in Psychology, 8, 2198 https://doi.org/10.3389/fpsyg.2017.02198

Katsurada, E., Tanimukai, M., \& Akazawa, J. (2017). A study of associations among attachment patterns, maltreatment, and behavior problem in institutionalized children in Japan. Child Abuse and Neglect, 70, 274-282. https://doi.org/10.1016/j.chiabu.2017.06.018

Khan, F., Fraley, R. C., Young, J. F., \& Hankin, B. L. (2020). Developmental trajectories of attachment and depressive symptoms in children and adolescents. Attachment and Human Development, 22(4), 392-408. https://doi.org/10.1080/14616734.2019.1624790

Madigan, S., Atkinson, L., Laurin, K., \& Benoit, D. (2013). Attachment and internalizing behavior in early childhood: A meta-analysis. Developmental Psychology, 49(4), 672689. 
Mash, E. J., \& Barkley, R. A. (2003). Child psychopathology (2nd Ed.).New York: Guilford Press. Merz, E. C., Tottenham, N., \& Noble, K. G. (2018). Socioeconomic status, amygdala volume, and internalizing symptoms in children and adolescents. Journal of Clinical Child and Adolescent Psychology, 47(2), 312-323. https://doi.org/10.1080/15374416.2017.1326122

Ministry of Education Malaysia. (2018). Maklumat Sekolah Di Negeri Selangor. Retrieved February 5, 2021, from http://www.data.gov.my/data/ms_MY/dataset/khairulizwan/resource/ee86f24d-9f0c4b04-8606-ba6c8712a25b

Ministry of Education Malaysia. (2019). Bilangan Murid Sekolah Rendah KPM 2019. Retrieved February 3, 2021, from http://www.data.gov.my/data/ms_MY/dataset/bilangan-muridsekolah-rendah-di-kpm-seperti-pada-30-september-2019/resource/80b5c1f5-43034e29-a570-c4d1bf39be79

National Health and Morbidity Survey. (2019). Non-communicable diseases, healthcare demand, and health literacy. Retrieved March 10, 2021, from http://iptk.moh.gov.my/images/technical_report/2020/4_Infographic_Booklet_NHMS_ 2019_-_English.pdf

Nunes, S. A. N., Faraco, A. M. X., Vieira, M. L., \& Rubin, K. H. (2013). Externalizing and internalizing problems: Contributions of attachment and parental practices. Psicologia: Reflexao e Critica, 26(3), 617-625. https://doi.org/10.1590/S0102-79722013000300022

Reiss, F. (2013). Socioeconomic inequalities and mental health problems in children and adolescents: a systematic review. Social science \& medicine, 90, 24-31.

Smeekens, S., Riksen-Walraven, J. M., \& Van Bakel, H. J. A. (2007). Multiple determinants of externalizing behavior in 5-year-olds: A longitudinal model. Journal of Abnormal Child Psychology, 35(3), 347-361. https://doi.org/10.1007/s10802-006-9095-y

Spruit, A., Goos, L., Weenink, N., Rodenburg, R., Niemeyer, H., Stams, G. J., \& Colonnesi, C. (2020). The relation between attachment and depression in children and adolescents: a multilevel meta-analysis. Clinical Child and Family Psychology Review, 23(1), 54-69. https://doi.org/10.1007/s10567-019-00299-9

World Health Organization. (2019). Adolescent Mental Health. Retrieved April 20, 2021, from https://www.who.int/news-room/fact-sheets/detail/adolescent-mental-health 